\title{
Simulação da dinâmica do carbono do solo numa microbacia rural pelo modelo Century
}

\author{
Fabíola Lopes ${ }^{(1)}$, Gustavo Henrique Merten ${ }^{(2)}$, João Mielniczuk ${ }^{(1)}$, Carlos Gustavo Tornquist ${ }^{(1)}$ \\ e Elisandra Solange Oliveira ${ }^{(1)}$
}

\begin{abstract}
(1)Universidade Federal do Rio Grande do Sul (UFRGS), Departamento de Solos, Avenida Bento Gonçalves, no 7712, CEP 91540-000 Porto Alegre, RS. E-mail: fabilopes@gmail.com, joão.mielniczuk@ufrgs.br, carlos.tornquist@ufrgs.br, elisandrao@pop.com.br (2)UFRGS, Instituto de Pesquisas Hidráulicas, Avenida Bento Gonçalves, № 9500, CEP 91501-970 Porto Alegre, RS. E-mail: merten@iph.ufrgs.br
\end{abstract}

Resumo - O objetivo deste trabalho foi combinar o modelo Century com técnicas de geoprocessamento e sensoriamento remoto, para avaliar a dinâmica espaço-temporal do carbono orgânico total do solo (COT). O estudo foi implementado numa microbacia rural, na encosta superior do Nordeste do Rio Grande do Sul, RS, que apresentava inicialmente uma cobertura florestal que foi convertida para agricultura, ao longo de 80 anos. A calibração adequada do modelo, principalmente dos parâmetros relacionados à decomposição do COT, nos anos iniciais de exploração agrícola, foi fundamental para possibilitar a simulação coerente dos valores de COT. Em relação à distribuição espacial do COT, foi verificado que o maior impacto da agricultura, sobre o estoque original de COT, ocorreu nas áreas sob cultivo desde 1925, nas quais se constatou decréscimo de 58,2\% do COT. Verificou-se que a integração do Century com um sistema de informações geográficas torna possível o estudo da dinâmica espaço-temporal do COT e a realização de inventários relativos à distribuição do COT.

Termos para indexação: Nicotiana tabacum, carbono orgânico do solo, geoprocessamento, sensoriamento remoto.

\section{Dynamics simulation of soil carbon in a small rural watershed by Century model}

\begin{abstract}
The objective of this study was to combine the Century model with geoprocessing and remote sensing techniques, in order to evaluate spatial-temporal dynamics in total organic carbon (TOC). The study was carried out in a small rural watershed in Northeastern of Rio Grande do Sul State, Brazil. The area was initially under forest cover, which was progressively converted to agriculture in a period of 80 years. The proper calibrating of the model, especially in terms of TOC decomposition parameters, during the initial years of tillage, was essential to produce a coherent simulation of TOC values. Regarding the spatial distribution of TOC, it was observed that greatest impact of soil management on original contents occurred in the areas under cultivation since 1925 , which showed a decline of $58.2 \%$ in TOC. The Century model integration with a geographic information system makes it possible the study of spatial-temporal dynamics of TOC and the performing of TOC distribution inventories.
\end{abstract}

Index terms: Nicotiana tabacum, soil organic carbon, geoprocessing, remote sensing.

\section{Introdução}

As atuais evidências da contribuição do $\mathrm{CO}_{2}$ atmosférico, para o aquecimento global, têm aumentado o interesse no carbono orgânico total (COT) do solo, por ser um dos principais compartimentos do ciclo terrestre do carbono (Cerri et al., 2003; Lal, 2004). Entre as muitas abordagens para se estimarem as alterações nos estoques de COT, a utilização de modelos de simulação tem se mostrado eficiente, pois permite estudar cenários históricos e futuros, por meio do conhecimento atual da dinâmica do COT (Cerri et al., 2003, 2004; Leite et al., 2004; Tornquist, 2007).

Os modelos de simulação do COT, geralmente, fornecem dados pontuais que levam em consideração apenas a sua variação no tempo. A modelagem dinâmica espacialmente explícita é uma alternativa para a análise da dinâmica e dos estoques do COT e incorpora, além da variabilidade temporal, a variabilidade espacial do COT do solo. Nørgaard (2004), ao visar este tipo de aplicação, integrou o modelo Century com um sistema de informações geográficas (SIG), que originou de forma 
espacializada a evolução dos estoques de COT no Senegal. Trabalho semelhante foi realizado por Tornquist (2007), em que por meio do desenvolvimento de uma metodologia de integração do modelo Century com um SIG, foi possível avaliar as mudanças de estoques de COT ocorridas na região do Município de Ibirubá, RS, desde o início da agricultura em 1900 até 2050.

Este trabalho teve como propósito utilizar o modelo de simulação Century (Parton, 1987), combinado com técnicas de geoprocessamento e sensoriamento remoto, para avaliar a dinâmica espaço-temporal do COT, na escala de uma microbacia rural.

\section{Material e Métodos}

Este estudo foi desenvolvido em uma microbacia hidrográfica rural, no Município de Arvorezinha, na encosta superior do Nordeste do Rio Grande do Sul, RS. O relevo apresenta topografia plana, no seu terço inicial (nascentes), e mais acidentada nos demais trechos. $\mathrm{O}$ ambiente, em conseqüência do extrativismo e da agricultura, está bastante alterado, e há apenas resquícios da vegetação nativa (Floresta Ombrófila Mista e Floresta Ombrófila Aberta).

A área total da microbacia é de 119 ha, composta por 16 propriedades. O uso atual do solo é constituído por: áreas de mata, junto às áreas de reflorestamento e pousio, que ocupam $27,2 \%$ da área; agricultura com $63,3 \%$; e pastagens com 9,5\%. O sistema de produção predominante é caracterizado por pequenas unidades familiares, que cultivam o fumo (Nicotiana tabacum), em sistema integrado com empresas fumageiras.

O mapa de solos na escala de 1:25.000 foi elaborado a partir de um levantamento de campo, realizado na microbacia (Fepagro, 2005). As classes taxonômicas de solos identificadas foram agrupadas em cinco unidades de mapeamento (UM), combinadas na forma de associação de solos (Tabela 1).

Na compilação do mapa de solos, objetivou-se maior simplificação das associações encontradas nas cinco UM, que levou em consideração a proporção estimada de cada componente da associação agrupado em três

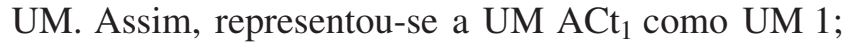
as $\mathrm{UM} \mathrm{CXvd}_{1}$ e $\mathrm{CXvd}_{4}$ como UM 2, e as UM RRd $\mathrm{UR}_{3}$ e $\mathrm{RRd}_{1}$ como UM 3 (Figura 1).

Para a elaboração do mapa, que descreve o ano em que a vegetação inicial da bacia foi convertida em área de cultivo, foi resgatada a história da evolução do uso do solo da microbacia, de acordo com o ano em que as áreas foram convertidas para áreas de lavoura, com base em dados censitários, entrevistas e registros de sensoriamento remoto.

O registro aerofotogramétrico mais antigo disponível consistiu em fotografias na escala de 1:60.000, datadas de 1965. A partir delas, foi delineada e ampliada a área da microbacia para a escala 1:25.000, e foi realizada a fotointerpretação, tendo-se construído um mapa vetorial que representa a vegetação de 1965 .

A taxa de conversão de floresta em agricultura entre 1915 - data da chegada das primeiras três famílias à microbacia - e 1965, foi estimada com base em dados censitários do IBGE de 15\% a cada 10 anos. Esta taxa foi utilizada para espacializar a expansão do desmatamento, tendo-se partido da localização aproximada das três famílias na microbacia em 1915. Com essas informações, construíram-se mapas de evolução do desmatamento entre: 1915 e 1925; 1925 e 1935; e 1935 e 1945. Com a aerofoto de 1965, determinou-se a ocupação do solo (desmatamento) entre 1915 e 1965.

A partir de 1965, a evolução do uso do solo foi reconstituída de 20 em 20 anos, por meio da classificação supervisionada de imagens LANDSAT, apoiada em

Tabela 1. Identificação das Unidades de Mapeamento (UM) da microbacia, com o símbolo da composição de solos e a proporção estimada de cada componente da associação de solos.

\begin{tabular}{|c|c|c|c|}
\hline$\overline{\mathrm{UM}}$ & Símbolo da composição & Composição da Unidade de Mapeamento & $\begin{array}{l}\text { Proporção estimada dos } \\
\text { componentes }(\%)\end{array}$ \\
\hline$\overline{\mathrm{UM}} 1: \mathrm{ACt}_{1}$ & $\mathrm{ACt} 1+\mathrm{CXvd}+\mathrm{RRd}$ & $\begin{array}{l}\text { Alissolo Crômico argilúvico abrúptico + Cambissolo Háplico Ta distrófico } \\
\text { típico + Neossolo Regolítico distrófico típico } \\
0 \text { a } 10 \% \text { de declive }\end{array}$ & 40,35 e 25 \\
\hline$\overline{\mathrm{UM}}$ 2: $\mathrm{CXvd}_{1}$ & $\mathrm{CXvd}+\mathrm{RRd}+\mathrm{ACt} 1$ & $\begin{array}{l}\text { Cambissolo Háplico Ta distrófico típico + Neossolo Regolítico distrófico típico } \\
+ \text { Alissolo Crômico argilúvico abrúptico } \\
10 \text { a } 20 \% \text { de declive }\end{array}$ & 40,30 e 30 \\
\hline $\mathrm{CXvd}_{4}$ & $\overline{\mathrm{CXvd}+\mathrm{RRd}}$ & $\begin{array}{l}\text { Cambissolo Háplico Ta distrófico típico + Neossolo Regolítico distrófico típico } \\
0 \text { a } 10 \% \text { declive }\end{array}$ & 60 e 40 \\
\hline UM 3: $\mathrm{RRd}_{3}$ & CXvd+RRd & $\begin{array}{l}\text { Neossolo Regolítico distrófico típico + Cambissolo Háplico Ta distrófico típico } \\
>30 \% \text { declive }\end{array}$ & 60 e 40 \\
\hline $\mathrm{RRd}_{1}$ & $\overline{R R d}+\mathrm{CXvd}$ & $\begin{array}{l}\text { Neossolo Regolítico distrófico típico + Cambissolo Háplico Ta distrófico típico } \\
10 \text { a } 20 \% \text { declive }\end{array}$ & 60 e 40 \\
\hline
\end{tabular}


observações de campo. A identificação do uso atual do solo (ano 2004) foi estabelecida por caminhamento e georreferenciamento com GPS de navegação, em todas as glebas da microbacia, auxiliada por uma imagem de alta resolução espacial ("QuickBird”).

Para a confecção do mapa da evolução do uso do solo na microbacia, foram realizados cinco cruzamentos no programa SPRING 4.2, entre os mapas de diferentes períodos. Esses cruzamentos foram executados de dois em dois mapas, isto é, foi cruzado o mapa de mata (1915) com o mapa da área das lavouras em 1925; o mapa resultante foi cruzado com o mapa das lavouras em 1945, e assim por diante, até o último cruzamento das lavouras de 1985 com as lavouras até 2004. Assim, gerou-se o mapa final da evolução do uso do solo desses 80 anos de exploração agrícola na bacia, que representa as áreas que entraram em cultivo entre 1925 e 1945; 1945 e 1965; 1965 e 1985; e 1985 e 2004, designadas por agricultura desde 1925, 1945, 1965 e 1985.

Para estudar o comportamento dos estoques de COT ao longo do tempo, dividiu-se a área da bacia em áreas homogêneas, denominadas unidades de simulação (US). Nesta divisão, consideraram-se o tempo de agricultura e o tipo de solo. Assim, cada US foi espacialmente representada num mapa temático e, posteriormente, foi realizada a simulação com cenários de manejo bem definidos pelo modelo Century.

O mapa final com as diferentes US foi obtido por meio de cruzamentos, no Spring 4.2, do mapa de solos constituídos por três UM com o mapa com o agrupamento das áreas, por períodos de conversão em lavoura, formado por cinco diferentes períodos. A partir desses cruzamentos foi gerado o mapa com 12 US (Figura 2).

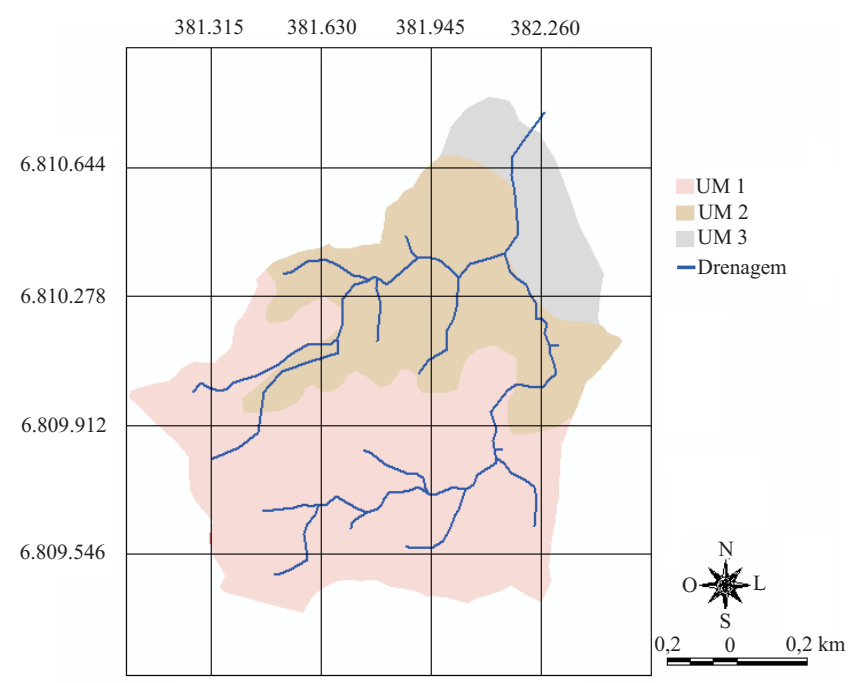

Figura 1. Mapa temático das Unidades de Mapeamento (UM).
Segundo Jørgensen \& Bandorocchio (2001), uma parte fundamental da modelagem é a calibração do modelo, que é definida como a tentativa de se estabelecer, por meio de variação de parâmetros internos do modelo, coincidências entre os dados medidos e os dados de saída do modelo.

O Century foi calibrado por meio de alterações nos parâmetros fixos (fix.100), de planta (crop.100), de floresta (tree.100) e de cultivo (cult.100), conforme descrito a seguir: a) a floresta utilizada no equilíbrio foi a BLEAF (floresta subtropical), onde os parâmetros PRDX (produção potencial de biomassa) foram alterados até que a variável SOMSC (variável de saída utilizada para o COT), após simulação de 6.000 anos, se estabilizasse, para coincidir com o valor médio do estoque de COT medido em campo; b) os parâmetros PRDX das culturas utilizadas foram alterados, para que as variáveis de saída AGLIVC (carbono na biomassa viva superficial) e BGLIVC (carbono na biomassa viva subsuperficial) se aproximassem dos valores considerados compatíveis com estas culturas; c) os parâmetros relacionados à relação $\mathrm{C} / \mathrm{N}$ da matéria orgânica do solo (MOS) que entra nos diferentes compartimentos foram alterados, para coincidir com valores considerados compatíveis com as culturas utilizadas. Estas modificações foram baseadas em consultas realizadas aos desenvolvedores do modelo (Colorado State University, Fort Collins, EUA) e na comprovação feita por Oliveira (2005), em trabalho que utilizou dados de um experimento de longa duração situado no Rio Grande do Sul. Assim, os parâmetros modificados foram dos compartimentos: lento VARAT2 $(1,1)$ - que aumentou o fator de multiplicação de 20 para 25, e passivo - VARAT3 $(1,1)$ - de 8 para 14. Adicionalmente, foi modificado o parâmetro VLOSSG (perda de $\mathrm{N}$ por volatilização), o qual passou de 0,010 para 0,013, de acordo com Oliveira (2005); e d) o efeito do preparo do solo, sobre a taxa de decomposição do compartimento lento, foi ajustado por meio da alteração do parâmetro CLTEFF(2) - multiplicador que aumenta a decomposição do referido compartimento no mês de cultivo - do CULT P, tendo-se criado dois diferentes para simulação nos diferentes períodos. Assim, nos primeiros três anos de cultivo, aumentou-se o CLTEFF (2) de 1,60 (valor padrão) para 3,20; nos 20 anos seguintes para 2,96; e nos últimos anos de exploração, manteve-se o valor-padrão (Oliveira, 2005). Além disso, para adequar o modelo para condições de solos cultivados, utilizou-se um efeito adicional de cultivo (CULT A), por dois meses seguidos após o revolvimento do solo, tendo-se prolongado, assim, o efeito do preparo 
sobre as taxas de decomposição da MOS observada nas condições locais (Leite et al., 2004).

Essas alterações permitiram refletir uma condição de campo já comprovada por diversos autores, em diferentes regiões do mundo (Veldkamp, 1994; Guo \& Gifford, 2002; Vanderbygaart et al., 2003), onde a conversão de uso do solo, sob vegetação nativa, para agricultura, em geral provoca grandes reduções do estoque de $\mathrm{C}$ nos anos iniciais. No Rio Grande do Sul, estudos em Latossolos registraram perdas entre 30 e $50 \%$ do estoque original de COT, cerca de 15 anos após conversão para a agricultura (Pöttker, 1977; Silva, 1980; Cintra et al.,
1983). Mello (2006), em trabalho realizado na mesma microbacia do presente estudo, verificou que áreas novas, de recente exploração agrícola, perdem por erosão maior quantidades da fração de CO particulado, por ser um sedimento fino e com baixa densidade.

A calibração foi executada na UM 2, composta da associação de solos CXvd+RRd+ACt1 e CXvd+RRd, com base nos estoques de COT em massa equivalente à floresta na camada de $0-20 \mathrm{~cm}$, de lavouras iniciadas a partir de áreas nativas, com tempo de exploração agrícola de 1, 25 e 40 anos de cultivo de fumo, sob sistema convencional determinados por Mello (2006).

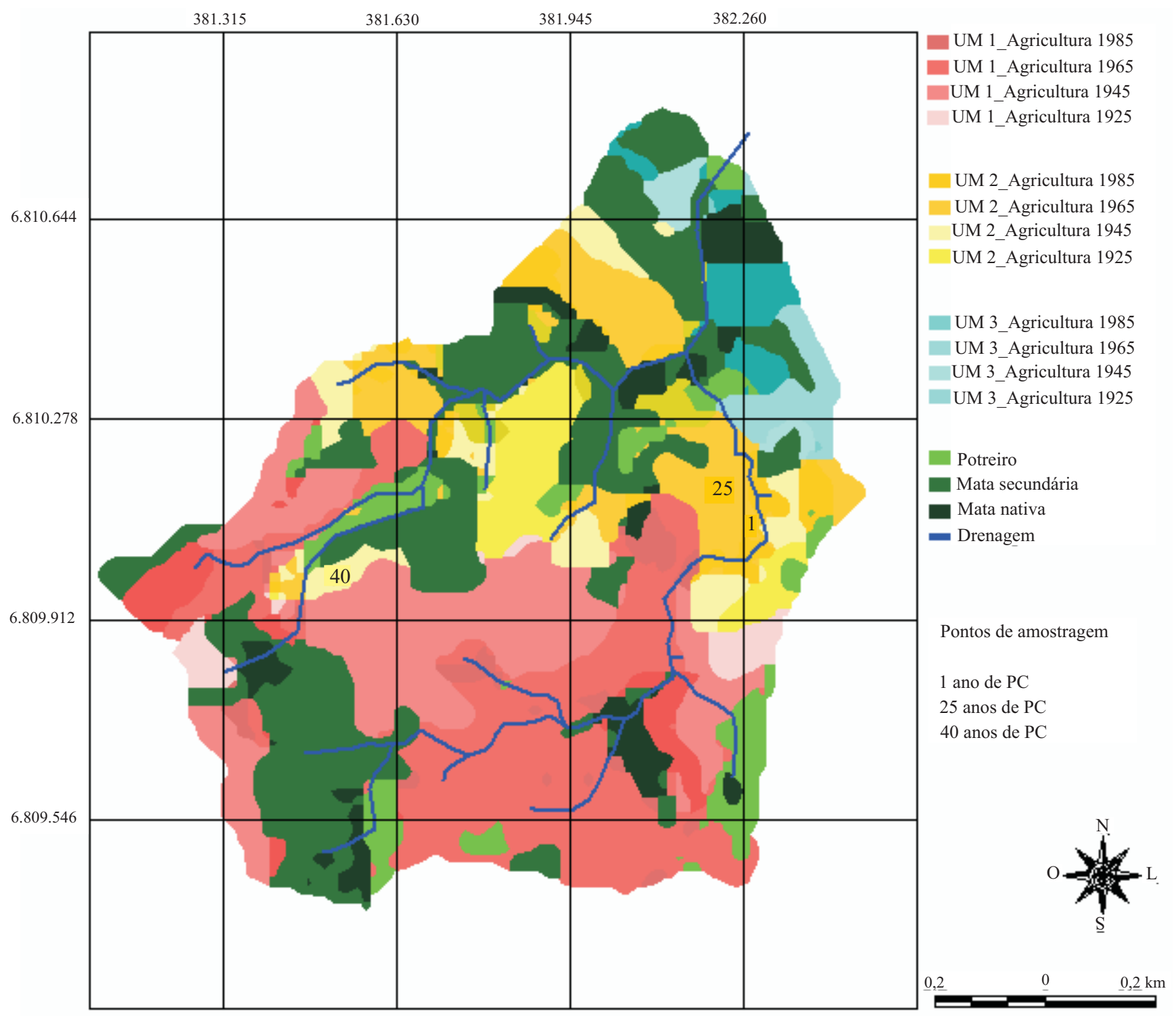

Figura 2. Representação espacial das unidades de simulação, utilizadas nas simulações pelo modelo Century, e localização dos pontos de amostragem do solo (Mello, 2006). 
Assumiu-se que o modelo tem o mesmo desempenho na UM 1 (ACt1+CXvd+RRd) e UM $3(\mathrm{CXvd}+\mathrm{RRd} /$ $\mathrm{RRd}+\mathrm{CXvd}$ ) (Tabela 1), pois essas UM não diferem significativamente da UM 2 usada na calibração, e possui características físicas e químicas semelhantes às UM 1 e 3.

As análises estatísticas, relativas à raiz quadrada do erro (RMSE) utilizada em experimentos onde há disponibilidade de repetições, foram empregadas para se verificar a acurácia das simulações, após as modificações dos parâmetros do modelo, em relação aos dados mensurados por meio do programa MODEVAL 1.1 (Smith et al., 1997).

Para as simulações, foram fornecidas as seguintes variáveis de entrada: média mensal, calculada a partir de dados diários, da temperatura (máxima e mínima) e da precipitação, de 1950 a 2000, da estação meteorológica do Município de Passo Fundo (8o DISME/ INMET); granulometria do solo das áreas de mata e lavoura (Mello, 2006); teor de lignina das plantas (retirado do arquivo CROP.100 do Century); quantidade de COT dos compartimentos ativo, lento e passivo (obtida pela execução de equilíbrio); dados de floresta subtropical (do arquivo TREE.100 do Century); e perdas de solo por erosão, em que se admitiram perdas de solo iguais entre os diferentes solos, na taxa de $10 \mathrm{Mg} \mathrm{ha}^{-1}$ por ano, aplicadas em dezembro de cada ano.

Na simulação das alterações no estoque de COT, a partir da condição de sistema estável (floresta subtropical), foram elaborados cenários de manejo que visaram a máxima semelhança com os manejos realizados pelos agricultores, na área entre os anos de 1915 e 2004. Esta informação histórica foi obtida por meio de entrevistas, realizadas com os antigos moradores da microbacia. Verificou-se que nos primeiros anos predominavam culturas coloniais, e que a partir dos anos 60, se iniciou a cultura do fumo e houve a ocorrência dos pousios longos, de aproximadamente 5 anos com capoeira, seguidos de 10 anos de cultivos. O início da simulação, em cada unidade de simulação, variou de acordo com o início da exploração agrícola em cada área (Tabela 2). Cabe ressaltar que os cenários constantes na Tabela 2 são aproximados, a história real é muito difícil ou mesmo impossível de ser reconstituída, em razão da lacuna de informação espacializada, entre o início do cultivo e os dias atuais.

As US de cada unidade de mapeamento (UM) partiram do estoque de COT, na camada de $0-20 \mathrm{~cm}$, com valor de 58,5 $\mathrm{Mg} \mathrm{ha}^{-1}$ na UM 1, 57,7 $\mathrm{Mg} \mathrm{ha}^{-1}$ na UM 2 e $56,9 \mathrm{Mg} \mathrm{ha}^{-1}$ na UM 3. Estes valores foram obtidos por meio da parametrização do Century, com a

Tabela 2. Cenários de manejo utilizados nas simulações com o modelo Century, das lavouras iniciadas em 1925, 1945, 1965 e 1985 até 2004.

\begin{tabular}{|c|c|c|}
\hline Cenário & Blocos/período & Descrição \\
\hline $\mathrm{I}$ & Colonial/1925-1965 & $\begin{array}{l}\text { Dois anos de milho com pousio outono/inverno, e um ano de trigo com pousio } \\
\text { verão/outono; lavração com tração animal; cultivares de baixo potencial de } \\
\text { rendimento, alta produção de biomassa. }\end{array}$ \\
\hline II & Entrada fumo/1966-1975 & $\begin{array}{l}\text { Fumo com pousio no inverno; preparo do solo com tração animal; adubação N } \\
\text { sintético ( } 100 \mathrm{~kg} \mathrm{ha}^{-1} \text { por ano). }\end{array}$ \\
\hline III & Pousio longo/1976-1980 & Pousio com gramíneas e capoeira. \\
\hline IV & Fumo-pousio/1981-1990 & $\begin{array}{l}\text { Fumo com pousio no inverno; preparo do solo com tração animal; adubação N } \\
\text { sintético (100 kg ha }{ }^{-1} \text { por ano). }\end{array}$ \\
\hline $\mathrm{V}$ & Pousio longo/1991-1995 & Pousio com gramíneas e capoeira. \\
\hline VI & Fumo-pousio/1996-2000 & $\begin{array}{l}\text { Fumo com pousio no inverno; preparo do solo com tração animal; adubação } \mathrm{N} \\
\text { sintético (100 kg ha }{ }^{-1} \text { por ano). }\end{array}$ \\
\hline $\mathrm{I}$ & Colonial/1945-1965 & $\begin{array}{l}\text { Dois anos de milho com pousio outono/inverno, e um ano de trigo com pousio } \\
\text { verão/outono; lavração com tração animal; cultivares de baixo potencial de } \\
\text { rendimento, alta produção de biomassa. }\end{array}$ \\
\hline$\overline{\mathrm{II}}$ & Entrada fumo/1966-1985 & $\begin{array}{l}\text { Fumo com pousio no inverno; preparo do solo com tração animal; adubação } \mathrm{N} \\
\text { sintético (100 } \mathrm{kg} \mathrm{ha}^{-1} \text { por ano). }\end{array}$ \\
\hline III & Pousio longo/1986-1990 & Pousio com gramíneas e capoeira. \\
\hline IV & Fumo-pousio/1990-2000 & $\begin{array}{l}\text { Fumo com pousio no inverno; preparo do solo com tração animal; adubação } \mathrm{N} \\
\text { sintético }\left(100 \mathrm{~kg} \mathrm{ha}^{-1} \text { por ano). }\right.\end{array}$ \\
\hline $\mathrm{V}$ & Fumo-aveia/2001-2004 & $\begin{array}{l}\text { Fumo com aveia; preparo do solo com tração animal; adubação sintética de } \mathrm{N} \\
\left(150 \mathrm{~kg} \mathrm{ha}^{-1} \text { por ano }\right) \text {. }\end{array}$ \\
\hline $\mathrm{I}$ & Fumo/1966-2000 & $\begin{array}{l}\text { Fumo com pousio no inverno; preparo do solo com tração animal; adubação N } \\
\text { sintético ( } 100 \mathrm{~kg} \mathrm{ha}^{-1} \text { por ano). }\end{array}$ \\
\hline II & Fumo-aveia/2001-2004 & $\begin{array}{l}\text { Fumo com aveia; preparo do solo com tração animal; adubação sintética de N } \\
\left(150 \mathrm{~kg} \mathrm{ha}^{-1} \mathrm{ano}^{-1}\right) \text {. }\end{array}$ \\
\hline$\overline{\mathrm{I}}$ & Fumo/1985-2000 & $\begin{array}{l}\text { Fumo com pousio no inverno, preparo do solo com tração animal, adubação } \mathrm{N} \\
\text { sintético ( } 100 \mathrm{~kg} \mathrm{ha}^{-1} \text { por ano). }\end{array}$ \\
\hline
\end{tabular}


execução de equilíbrio, e foram aproximados dos valores de COT obtidos em análises de amostras dos solos destas UM sob vegetação nativa (Mello, 2006).

Para a verificação do desempenho do modelo, nas diversas situações, os resultados das simulações foram contrastados com os dados obtidos na mesma microbacia por Mello (2006) e Emater/RS (Fepagro, 2005).

A espacialização dos dados, originados pelo modelo Century, foi realizada pela sua integração em um ambiente SIG, por meio da modelagem dinâmica espacialmente explícita com o acoplamento livre (Nørgaard, 2004). Nessa modelagem, os resultados das simulações pelo Century são transferidos manualmente de uma base de dados, separada estruturalmente, para um SIG, que representará os resultados, de forma espacializada. Assim, foi construído um mapa de distribuição espacial de COT para cada US, em um dado momento após o início da agricultura até determinado período; no presente estudo, de 1915 a 2004.

\section{Resultados e Discussão}

A taxa máxima de conversão da floresta em agricultura ocorreu por volta de 1965 e atingiu $75 \%$ de ocupação. A partir desse ano, houve declínio da área cultivada e aumento de áreas com vegetação permanente. A suposição que se faz para esse declínio é a de que as áreas que se encontravam em pousio evoluíram para a condição de mata secundária. Pela evolução temporal do uso do solo, verificou-se também que as áreas de potreiro, que se localizam acerca das residências, aumentaram ao longo do tempo, e esse crescimento coincide com a chegada das novas famílias de agricultores na área.

Em 1925, dos 7,4 ha ocupados com lavoura $70 \%$ encontravam-se sobre a UM 2 - composta pelos solos CXvd+RRd+ACt1 e CXvd+RRd-e $30 \%$ sobre a UM 1 - formada pelos solos ACt1+CXvd+RRd (Figura 2). Pode-se, assim, concluir que a agricultura se iniciou nas áreas menos declivosas, e que a região da UM 3 (mais declivosa e mais distante dos acessos e estradas da época), composta pelos solos CXvd+RRd e RRd+CXvd, não havia ainda sido explorada com a agricultura. Entre os anos de 1925 e 1945, a expansão ocorreu principalmente nas áreas das UM 1, provavelmente em razão da baixa declividade e da proximidade dessas áreas das estradas.
Entre os anos de 1945 e 1965, ocorreu a maior expansão agrícola da região, que coincidiu com o início do cultivo de fumo. De 1965 até 1985, houve redução no desmatamento, fato que é confirmado pelos dados dos anuários agrícolas do IBGE. Na área sobre a UM 3 , não houve expansão alguma nessa época, e estas áreas, provavelmente, ficaram em pousio durante esse período.

De 1985 a 2004, grande parte das áreas desmatadas ocorreram sobre as unidades UM 1 e 3 . Essa mesma situação não foi observada na UM 2, provavelmente porque nessa unidade, durante esse período, não havia grandes áreas sob vegetação nativa.

O modelo Century foi calibrado para as condições edafoclimáticas da microbacia, pelas alterações dos parâmetros já descritos (Figura 3). A análise estatística da raiz quadrada do erro (RMSE) mostrou que os valores simulados encontram-se dentro do intervalo de confiança $(95 \%)$ dos resultados mensurados. As modificações dos parâmetros foram imprescindíveis para a obtenção deste resultado, visto que foram necessárias para expressar a realidade de campo, pois os parâmetros do "default" do modelo foram desenvolvidos para regiões com clima e solo diferentes dos que ocorrem na microbacia. Este resultado mostra, também, que as alterações dos parâmetros foram condizentes, e aproximaram-se das condições reais de campo da microbacia.

Nas Figuras 4 e 5, são apresentados os resultados das simulações, realizadas nas diferentes US sobre as UM,

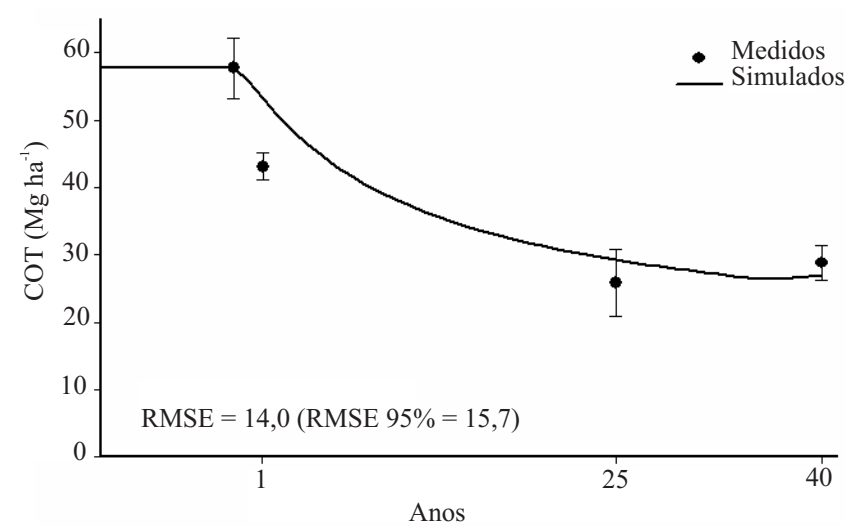

Figura 3. Resultados da simulação de calibração do modelo Century, contrapostos aos dados medidos de carbono orgânico total do solo (COT), em áreas sob cultivo do solo por 1,25 e 40 anos a partir de mata nativa. Cada ponto representa a média dos nove locais amostrados em cada área (Mello, 2006). 

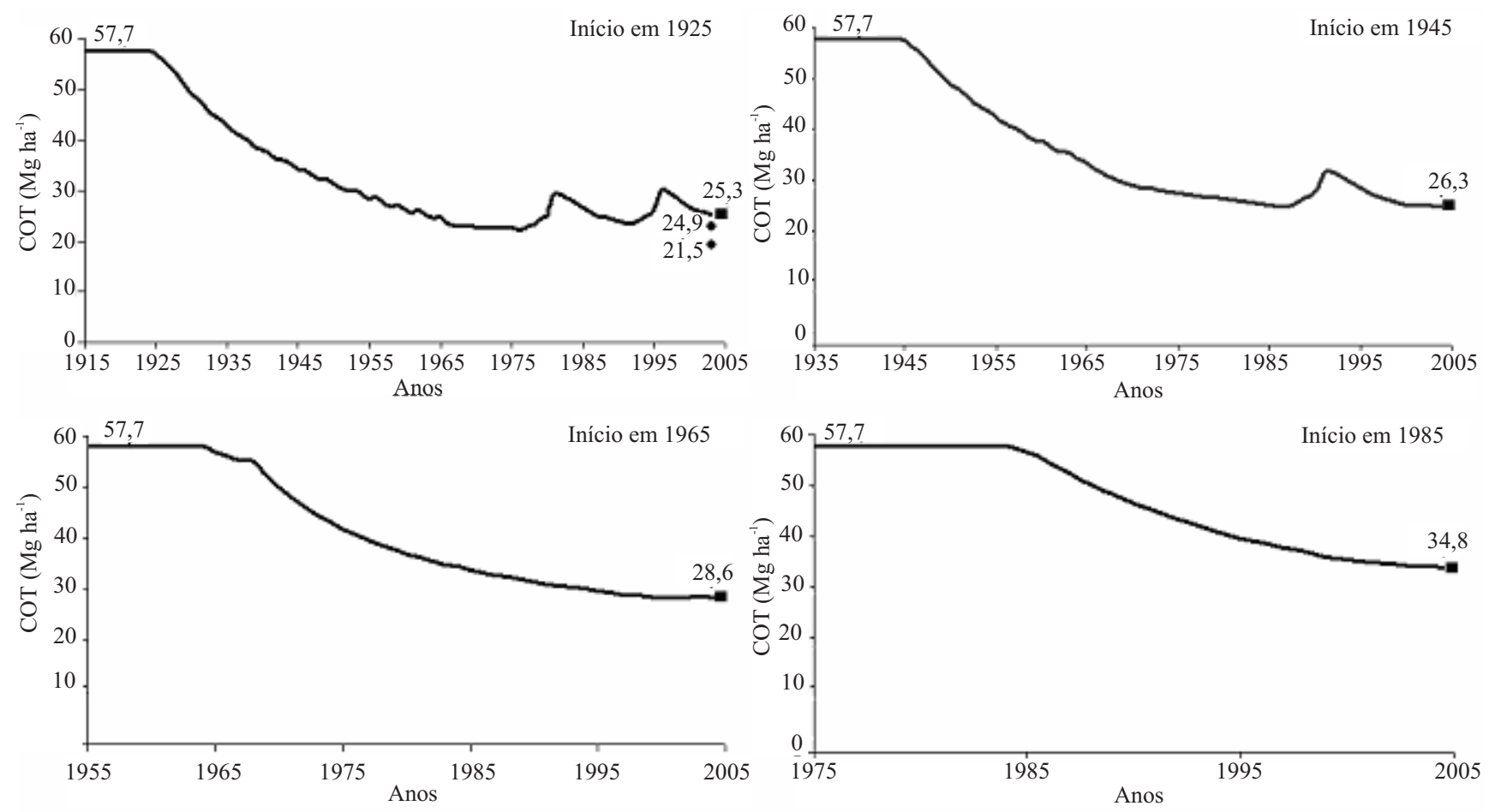

Figura 4. Carbono orgânico total do solo (COT) simulado ( $\mathbf{\square}$ ) pelo modelo Century e COT medido (•), em lavouras de aproximadamente 75 anos de cultivo (início em 1925), na camada de solo de 0-20 cm, para as quatro unidades de simulação sobre os solos da UM 2.
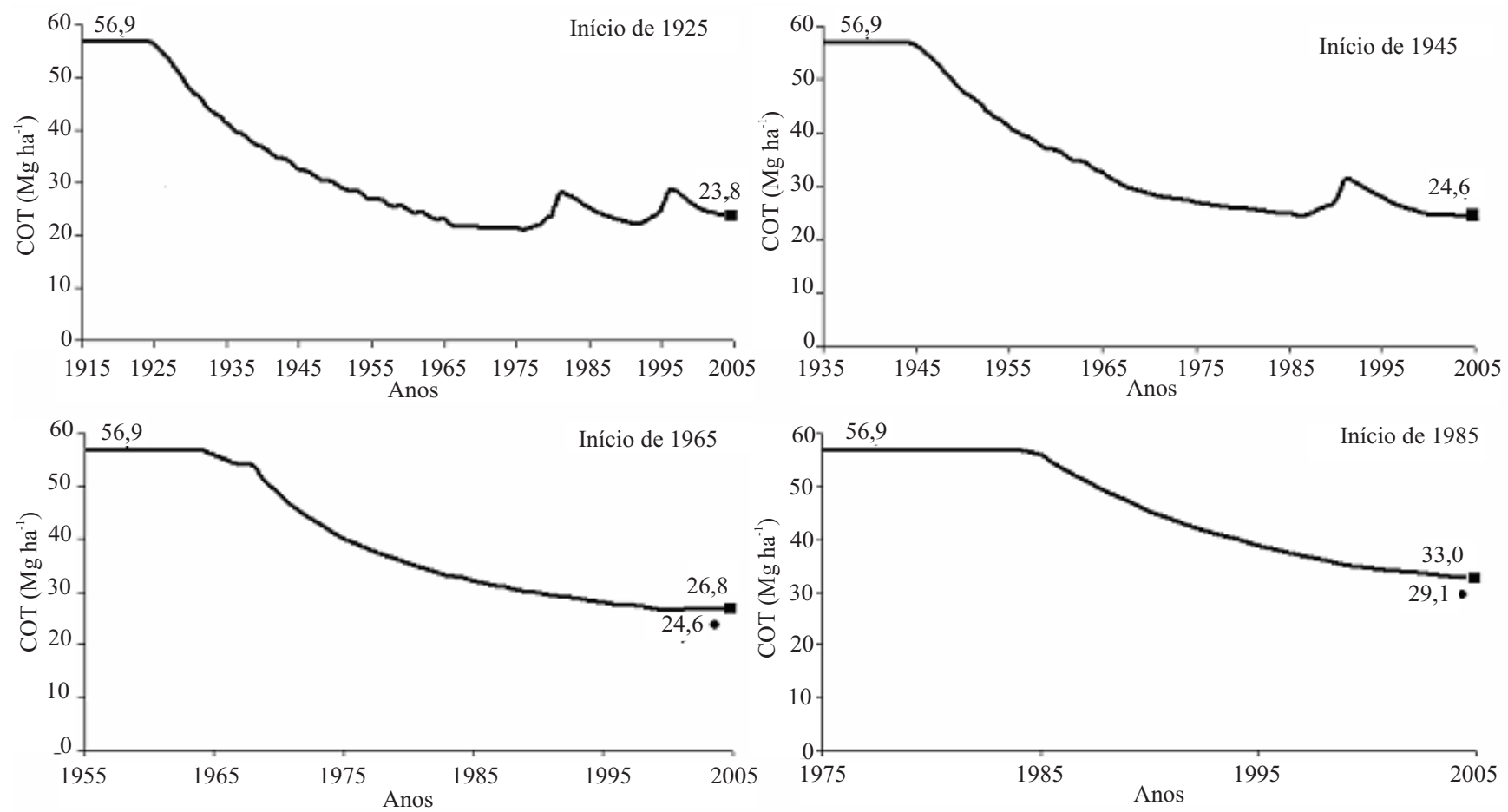

Figura 5. Carbono orgânico total do solo (COT) simulado (•) pelo modelo Century e COT medido (•), em lavouras de 40 e 20 anos de cultivo (início em 1965 e 1985), na camada de solo de 0-20 cm, para as quatro unidades de simulação sobre os solos da UM 3. 
que resultaram em teores de COT mais contrastantes (UM 2 e 3). A maior redução do COT na UM 3 em lavouras desde 1925 - decréscimo de 58,2\% no teor de COT original do solo (Figura 5) - ocorreu em razão do menor estoque de COT inicial nos solos da UM 3, quando comparado com os estoques iniciais das UM 1 e 2. Nas Figuras 4 e 5 verifica-se, também, que com a adição do pousio de cinco anos ao sistema - desenvolvimento maior de gramíneas e plantas lenhosas - ocorreu um acúmulo de COT no solo, ao longo do tempo, refletido nos picos observados nas lavouras iniciadas em $1925 \mathrm{e}$ 1945.

As lavouras cultivadas durante um longo período com a sucessão fumo-pousio, em preparo convencional (PC - aração e gradagem com tração animal) na microbacia, apresentaram significativa redução no teor de C (Fepagro, 2005; Mello, 2006), e chegaram à redução de 59\% no estoque inicial de COT, em uma lavoura sob a UM 2, ou seja, com valores próximos aos valores simulados pelo modelo.

Dados de campo levantados em um trabalho de caracterização física, química e biológica dos solos da microbacia, executado no ano de 2001, mostram que áreas de lavouras antigas, de aproximadamente 75 anos de cultivo sob a UM 2, apresentaram no ano de 2001 um estoque de C entre 21,5 e 24,9 $\mathrm{Mg} \mathrm{ha}^{-1}$, e a simulação nesta mesma UM apresentou, após 80 anos de cultivo, um estoque de 25,3 $\mathrm{Mg} \mathrm{ha}^{-1}$, o que mostra que o modelo simulou, nessa condição, situação muito semelhante com a medida no campo. $\mathrm{O}$ mesmo fato foi verificado com a comparação dos valores da UM 3 em que, por meio dos dados medidos a campo de uma área cultivada durante 40 anos determinou-se um estoque de C de 24,6 $\mathrm{Mg} \mathrm{ha}^{-1}$, e durante 20 anos, estoque de $29,1 \mathrm{Mg} \mathrm{ha}^{-1}$, enquanto que os valores de estoques de $\mathrm{C}$ simulados foram 26,5 $\mathrm{Mg} \mathrm{ha}^{-1}$ e 29,7 $\mathrm{Mg} \mathrm{ha}^{-1}$, respectivamente.

O modelo se comportou de maneira semelhante, em diversos outros trabalhos realizados no Brasil (Cerri et al., 2004; Leite et al., 2004; Tornquist, 2007), segundo os quais o estoque de COT passou, ao longo do tempo, por decréscimos de magnitudes diferentes, conforme o clima e o solo da região. Leite et al. (2004) verificaram boas correlações $\left(R^{2}=0,93, p<0,01\right)$ entre os estoques de COT medidos e simulados, o que evidencia a potencialidade do modelo para simular a dinâmica do COT, em solos sob diferentes sistemas de manejo.

A espacialização da distribuição do COT é uma aproximação da variabilidade dos valores reais de COT encontrados na microbacia (Figura 6). À medida que for possível se introduzirem mais variáveis para compor

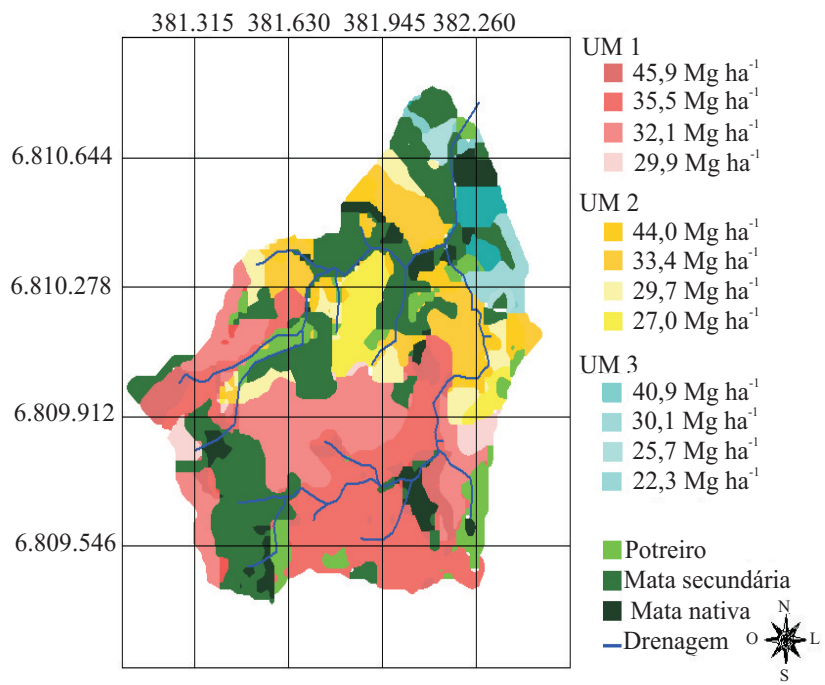

Figura 6. Estoque de carbono orgânico total do solo (COT) em massa equivalente à floresta, na camada de $0-20 \mathrm{~cm}$, estimado por meio da simulação nas 12 US, em 2004.

as US como, por exemplo, posições geomorfológicas do terreno e a distribuição espacial das áreas de erosão e deposição de sedimentos, melhor se poderá discretizar a variabilidade espacial do COT.

\section{Conclusão}

O modelo Century mostra-se adequado para simular a dinâmica espaço-temporal do carbono orgânico total do solo, numa microbacia rural, após a sua parametrização com dados locais de clima e solo e a posterior calibração.

\section{Referências}

CERRI, C.E.P.; BERNOUX, M.; CHAPLOT, V.; VOLKOFF, B.; VICTORIA, R.L.; MELILLO, J.M.; PAUSTIAN, K.; CERRI, C.C. Assessment of soil property spatial variation in an Amazon pasture: basis for selecting an agronomic experimental area. Geoderma, v.123, p.51-68, 2004.

CERRI, C.E.P.; COLEMAN, K.; JENKINSON, D.S.; BERNOUX, M.; VICTORIA, R.; CERRI, C.C. Modeling soil carbon from forest and pasture ecosystems of Amazon, Brazil. Soil Science Society of America Journal, v.67, p.1879-1887, 2003.

CINTRA, F.L.D.; MIELNICZUK, J.; SCOPEL, I. Caracterização de impedimento mecânico em um Latossolo Roxo do Rio Grande do Sul. Revista Brasileira de Ciência do Solo, v.7, p.323-327, 1983.

FEPAGRO. Projeto de monitoramento ambiental de microbacias hidrográficas do programa RS Rural: relatório final. Porto Alegre: Fepagro, 2005. 215p.

GUO, L.B.; GIFFORD, R.M. Soil carbon stocks and land use change: a meta analysis. Global Change Biology, v.8, p.345-360, 2002. 
JØRGENSEN, S.E.; BENDOROCHIO, G. Fundamentals of ecological modelling. $3^{\text {rd }}$ ed. New York: Elsevier, 2001. 530p. (Developments in Environmental Modelling, 21).

LAL, R. Soil carbon sequestration to mitigate climate change. Geoderma, v.13, p.1-22, 2004.

LEITE, L.F.C.; MENDONÇA, E.S.; MACHADO, P.L.O.A.; FERNANDES FILHO, E.I.; NEVES, J.C.L. Simulating trends in soil organic carbon of an Acrisol under no-tillage and disc-plow systems using the Century model. Geoderma, v.120, p.283-295, 2004.

MELLO, N.A. Efeito do sistema de manejo nos atributos do solo, movimentação de sedimentos e exportação de carbono orgânico numa microbacia rural sob cultura do fumo. 2006. 248p. Tese (Doutorado) - Universidade Federal do Rio Grande do Sul, Porto Alegre.

NØRGAARD, A. Spatial modelling of soil organic carbon by linking Century and GIS. 2004. 164p. Thesis (Ph.D.) - University of Copenhagen, Copenhagen.

OLIVEIRA, E.S. Uso do modelo Century no estudo da dinâmica do nitrogênio em um Argissolo do Rio Grande do Sul. 2005. 114p. Dissertação (Mestrado) - Universidade Federal do Rio Grande do Sul, Porto Alegre.

PARTON, W.J.; SCHIMEL, D.S.; COLE, C.V.; OJIMA, D.S. Analysis of factors controlling soil organic matter levels in great plains grasslands. Soil Science Society of America, v.51, p.11731179, 1987.
PÖTTKER, D. Efeitos do tipo de solo, tempo de cultivo e da calagem sobre a mineralização da matéria orgânica em solos do Rio Grande do Sul. 1977. 85p. Dissertação (Mestrado) Universidade Federal do Rio Grande do Sul, Porto Alegre.

SILVA, I.F. Efeitos de sistemas de manejo e tempo de cultivo sobre propriedades físicas de um Latossolo. 1980. 85p. Dissertação (Mestrado) - Universidade Federal do Rio Grande do Sul, Porto Alegre.

SMITH, P.; SMITH, J.U.; POWLSON, D.S.; MCGILL, W.B.; ARAH, J.R.M.; CHERTOV, O.G.; COLEMAN, K.; FRANKO, U.; FROLKING, S.; JENKINSON, D.S.; JENSEN, L.S.; KELLY, R.H.; KLEIN GUNNEWIEK, H.; KOMAROV, A.S.; LI, C.; MOLINA, J.A.E.; MUELLER, T.; PARTON, W.J.; THORNLEY, J.H.M.; WHITMORE, A. A comparison of the performance of nine soil organic matter models using datasets from seven long-term experiments. Geoderma, v.81, p.153-225, 1997.

TORNQUIST, C.G. Simulação da dinâmica do carbono orgânico do solo em escala regional: aplicação do modelo Century e sistemas de informações geográficas. 2007. 156p. Tese (Doutorado) Universidade Federal do Rio Grande do Sul, Porto Alegre.

VANDERBYGAART, A.J.; GREGORICH, E.G.; ANGERS, D.A. Influence of agricultural management on soil organic carbon: a compendium and assessment of Canadian studies. Canadian Journal of Soil Science, v.83, p.363-380, 2003.

VELDKAMP, E. Organic carbon turnover in three tropical soils under pasture after deforestation. Soil Science Society of America Journal, v.58, p.175-180, 1994.

Recebido em 22 de janeiro de 2008 e aprovado em 27 de maio de 2008 